\title{
Race and racism in the geosciences
}

\author{
Geoscientists in the United States are predominantly White. Progress towards diversification can only come with a \\ concerted shift in mindsets and a deeper understanding of the complexities of race.
}

\section{Kuheli Dutt}

T he geosciences are among the least diverse science, technology, engineering and mathematics (STEM) fields in the United States, with almost $90 \%$ of doctoral degrees awarded to White people ${ }^{1}$. And racial diversity in $\mathrm{PhD}$-level Earth scientists has not improved over the past four decades, with faculty of colour holding only $3.8 \%$ of tenured or tenure track positions in the top 100 geoscience departments ${ }^{2}$. The less diverse a field, the less welcoming it is to minorities, and the more prevalent implicit biases become. Combined with structural and social factors, the relative homogeneity in geoscience reinforces the dominant culture. As a result, women $^{3}$, people from sexual and gender minorities ${ }^{4}$, and Black and Hispanic people ${ }^{5}$ all leave the field at higher rates than the average student or practitioner.

The term 'colourblind racism' ${ }^{6}$ is used to describe the declaration that someone simply does not see colour, denoting a subtler form of racism than overt racism. Many White people who are not aware of (and would deny having) any racist tendencies unwittingly engage in it. Although this is not intentional, disregarding race in a setting with a strong imbalance in power - as is the case in many US geoscience departments - reinforces race being viewed by default from a perspective of being White.

\section{Racism versus prejudice}

Racism and prejudice are distinct, in that racism denotes a systemic advantage that benefits a dominant group, such as White people, whereas prejudice suggests individual bias. People of any race can be prejudiced, yet systemic racism is not so much about prejudice as it is about a power differential between majority and minority groups. Many White people do not acknowledge systemic racism. This can be perceived by people of colour as a lack of awareness, or as a lack of caring from those who are not exposed to it.

As the Diversity Officer for a geoscience campus with predominantly White students and staff, I have noticed a consistent pattern: there is a massive disconnect between how White people and people of colour view race. People of colour tend to view race as an important part of their identity, whereas White people tend to view it as incidental. Moreover, references to race and racism often make people of colour feel seen and heard, whereas White people tend to view such references as unnecessary or even inappropriate. Another consistent pattern I have noticed is that most people of colour do not feel comfortable discussing race with White colleagues. This is not because they think those White people are bad people - on the contrary, I often hear glowing accounts about mentors and supervisors. But people of colour fear that such discussions might trigger tensions that they want to avoid, especially in hierarchical settings such as academia.

\section{"Most people of colour do not}

feel comfortable discussing race with White colleagues.

This is not because they think

\section{those White people are}

\section{bad people."}

Implicit racism is deeply embedded in US society, and geoscience culture is no exception. A lack of awareness exacerbates the problem. First, many individuals who are privileged by belonging to dominant groups do not feel responsible for the systemic racism in that culture. Second, the subject of privileges that White researchers enjoy is an uncomfortable topic as many White people equate it with being implicated in racism, feeling that it challenges their identities as good people. This is a misconception: having privileges as a consequence of being White does not mean that one has not experienced other forms of oppression, it just means that racism is not one of them. Third, when it is the norm to be White, maintaining the comfort of White people becomes part of the unwritten code of a culture, a code that people of colour often follow.

\section{Oblivious to bias}

Not acknowledging this bias means that the realities of people of colour are dismissed, often by obliviousness rather than out of malice. For example, the 2019 Survey of US College and University Presidents ${ }^{7}$ showed that whereas only $25 \%$ of presidents viewed race relations on college campuses overall as good or excellent, $81 \%$ of presidents rated race relations on their own campus as good or excellent. Furthermore, in US colleges, more than $80 \%$ of presidencies and $75 \%$ of managerial positions are held by White people. That is, people who do not experience systemic racial oppression themselves end up dominating the racial narrative, regardless of the actual experiences of people of colour.

Earlier this summer, our graduate students were targeted with hateful, racist e-mails from an anonymous sender. Many were shaken by the incident, and we took the opportunity to open up a deeper conversation on campus about race and racial bias. There was widespread condemnation of the incident. However, people responded differently in terms of the ownership that they felt when a minority group was attacked. Whereas some engaged in community events around the incident, others expressed concern that they were being asked to attend a racial bias training despite not being responsible for the e-mails. If we truly want to create an inclusive geoscience culture, dominant groups need to take ownership, instead of minorities bearing the burden ${ }^{8}$.

This is easier said than done, when different groups do not even see the problem through the same lens. A survey by the Pew Center on perceptions of race and inequality in the United States found profound differences between Black and White adults, with $88 \%$ of Black respondents expressing that racial inequality needed to be addressed, compared with only $53 \%$ of White respondents ${ }^{9}$. In a different study that included STEM and non-STEM faculty, as well as people from the general public, men tended to be more skeptical of gender bias research than women, and this was especially prominent among male STEM faculty ${ }^{10}$. These results suggests that people who don't experience a certain type of inequity tend to dismiss it more easily than those who do. If the experiences of minorities are collectively dismissed, that 
can lead to a feeling of not belonging, which in the geosciences is a powerful force that can drive minorities away from the field ${ }^{11}$.

Diversity and inclusion cannot exist without a sense of belonging. We need to acknowledge people's identities for them to feel included. Focusing on diversity without inclusion makes marginalized groups feel that they merely serve as a diversity statistic, and that in reality their voices and experiences do not count. Besides, the culture of objectivity, or being removed from the subject matter - which is essential for science - works abysmally for topics like racism, where feelings, emotions, and identities play an enormous role.

\section{Individual responsibility}

On a personal level there are three things that White geoscientists can do immediately. First, they should separate their privilege as a White person from their identity as a good person. Conflating the two leads to feelings of anger, denial and defensiveness, because racism tends to be viewed as a character defect rather than the system of advantage and social conditioning that it really is. Second, to see these issues more clearly, White people need to better understand the perspectives of people of colour by, for example, reading about them ${ }^{6,12,13}$. These topics are uncomfortable, and often evoke strong reactions, but avoiding them will only worsen the problem. Those in positions of privilege should regularly ask themselves what they are doing to combat racism and promote inclusion, as a simple, but effective, reality check. Third, White people need to engage in discussions about race with other White people to move the dial from personal awareness to addressing the dominant culture, ideally in campus-wide dialogues. It is important to avoid putting minorities on the spot: just as there is no single White opinion on race, there is no single Black or Latinx or Asian opinion.

At an institutional level, leaders need to be especially proactive. Affinity bias - the tendency to prefer people like ourselves - is extremely powerful and exists within each of us. When the leadership is predominantly White, new faculty and leadership appointments are often White. This is sometimes blamed on the low percentage of minorities in geoscience, but the reality is more complex: we tend to see merit in people who resemble us. More people of colour need to be appointed to leadership positions, and we need to invest in minority students ${ }^{14}$ and faculty ${ }^{15}$.

Diversity and inclusion need to be prioritized in institutional procedures such as search and awards committees. Furthermore, bias training needs to be considered on a par with scientific and technical training. To set an example, institutional leaders should visibly and actively participate in bias trainings ${ }^{16}$. There are mixed opinions about the efficacy of bias trainings, as it takes more than training to transform a culture. Nevertheless, bias trainings are still an essential first step towards better understanding race and racism.

A lack of diversity and inclusion is the single largest cultural problem facing the geosciences today, and this is probably not just limited to the United States. We need a systemic cultural change that can only happen when people are not only willing to acknowledge the problem, but also to take individual responsibility for it. The only way we can change the geoscience culture is by a massive shift in individual mindsets, with the aim of moving the field from passively non-racist to actively anti-racist.

\section{Kuheli Dutt}

Lamont-Doherty Earth Observatory, Columbia University, New York, NY, USA. e-mail: kdutt@ldeo.columbia.edu

Published online: 16 December 2019 https://doi.org/10.1038/s41561-019-0519-z

References

1. Status of the Geoscience Workforce (American Geosciences Institute, 2016).

2. Bernard, R. E. \& Cooperdock, E. H. Nat. Geosci. 11, 292-295 (2018)

3. Holmes, M. A., OConnell, S. \& Dutt, K. Women in the Geosciences: Practical, Positive Practices Toward Parity (American Geophysical Union, 2015).

4. Hughes, B. E. Sci. Adv. 4, eaao6373 (2018)

5. Riegle-Crumb, C., King, B. \& Irizarry, Y. Educ. Res. 48 133-144 (2019).

6. Bonilla-Silva, E. Racism Without Racists: Color-blind Racism and the Persistence of Racial Inequality in the United States (Rowman \& Littlefield, 2017).

7. 2019 Survey of College and University Presidents: A Study by Inside Higher Ed and Gallup (Inside Higher Ed, 2019).

8. Jimenez, M. F. et al. Nat. Ecol. Evol. 3, 1030-1033 (2019).

9. On Views of Race and Inequality, Blacks and Whites are Worlds Apart (Pew Research Center, 2016).

10. Handley, I. M., Brown, E. R., Moss-Racusin, C. A. \& Smith, J. L. Proc. Natl Acad. Sci. USA 112, 13201-13206 (2015).

11. Huntoon, J. E., Tanenbaum, C. \& Hodges, J. Eos 96, https://doi org/10.1029/2015EO025897 (2015).

12. DiAngelo, R. White Fragility: Why it's so Hard for White People to Talk About Racism (Beacon, 2018).

13. Sue, D. W. Race Talk and the Conspiracy of Silence (Wiley, 2016).

14. Stokes, P. J., Levine, R. \& Flessa, K. W. J. Geosci. Educ. 63 250-263 (2015).

15. Baber, L. D., Pifer, M. J., Colbeck, C. \& Furman, T. J. Geosci. Educ. 58, 32-42 (2010).

16. Reducing the Impact of Bias in the STEM Workforce (National Science Foundation, 2016). 